\title{
Effect of SiC Nanowhisker on the Microstructure and Mechanical Properties of WC-Ni Cemented Carbide Prepared by Spark Plasma Sintering
}

\author{
Xiaoyong Ren, Zhijian Peng, Zhiqiang Fu, and Chengbiao Wang \\ Key Laboratory on Deep GeoDrilling Technology of the Ministry of Land and Resources, School of Engineering and Technology, \\ China University of Geosciences, Beijing 100083, China
}

Correspondence should be addressed to Zhijian Peng; pengzhijian@cugb.edu.cn

Received 11 March 2014; Accepted 19 May 2014; Published 3 June 2014

Academic Editor: Faik Oktar

Copyright (C) 2014 Xiaoyong Ren et al. This is an open access article distributed under the Creative Commons Attribution License, which permits unrestricted use, distribution, and reproduction in any medium, provided the original work is properly cited.

\begin{abstract}
Ultrafine tungsten carbide-nickel (WC-Ni) cemented carbides with varied fractions of silicon carbide (SiC) nanowhisker (03.75 wt.\%) were fabricated by spark plasma sintering at $1350^{\circ} \mathrm{C}$ under a uniaxial pressure of $50 \mathrm{MPa}$ with the assistance of vanadium carbide (VC) and tantalum carbide (TaC) as WC grain growth inhibitors. The effects of SiC nanowhisker on the microstructure and mechanical properties of the as-prepared WC-Ni cemented carbides were investigated. X-ray diffraction analysis revealed that during spark plasma sintering (SPS) $\mathrm{Ni}$ may react with the applied $\mathrm{SiC}$ nanowhisker, forming $\mathrm{Ni}_{2} \mathrm{Si}$ and graphite. Scanning electron microscopy examination indicated that, with the addition of $\mathrm{SiC}$ nanowhisker, the average WC grain size decreased from 400 to $350 \mathrm{~nm}$. However, with the additional fractions of SiC nanowhisker, more and more Si-rich aggregates appeared. With the increase in the added fraction of $\mathrm{SiC}$ nanowhisker, the Vickers hardness of the samples initially increased and then decreased, reaching its maximum of about $24.9 \mathrm{GPa}$ when $0.75 \mathrm{wt}$.\% SiC nanowhisker was added. However, the flexural strength of the sample gradually decreased with increasing addition fraction of $\mathrm{SiC}$ nanowhisker.
\end{abstract}

\section{Introduction}

WC-based cemented carbide is a class of important tool material, which has been applied in metal cutting, wood machining, rock drilling, and electronics industries because of its high hardness, good wear resistance, and excellent toughness [1-3]. Now cemented carbides are also increasingly used as seal rings, linings, valves, jet nozzles, saw blades, fluid mixers, and conveyor belt scrapers due to their excellent wear resistance and chemical stability $[4,5]$. Generally, cobalt $(\mathrm{Co})$ is used as a binder metal in cemented carbides because of its excellent wetting ability to WC and the outstanding mechanical strength of WC-Co [6]. However, the relative low corrosion resistance of WC-Co and high price of Co have limited the applications of cemented carbides as wear parts to some extent in corrosive/oxidative environments, where the components may be expected to remain in service for several years. Moreover, the leaching of Co-based binder can also be hazardous for health since Co is carcinogenic [5]. Thereby, considerable efforts have been focused on the partial or complete replacement of Co by other metallic binders in recent years. Now, $\mathrm{Ni}$ is regarded as a desirable one since it presents similar wetting ability to WC, and these cemented carbides exhibited higher corrosion and oxidation resistance than their WC-Co counterparts as well [7-10]. However, because $\mathrm{Ni}$ has much lower hardness and strength values than $\mathrm{Co}$, correspondingly WC-Ni cemented carbides also possess relatively lower values than WC-Co cemented carbides, which limits the complete substitution of WC-Ni with WCCo in applications $[8,11-13]$.

According to Hall-Petch relation, the hardness of cemented carbides can be improved with the decrease in WC grain size [3, 12-17]. Therefore, the development of finer grained WC-Ni becomes important to enhance the hardness of the WC-Ni cemented carbides. In order to suppress the grain growth during sintering, fast sintering techniques, such as spark plasma sintering (SPS) and high frequency induction heating sintering (HFIHS), and grain growth inhibitors, such as $\mathrm{VC}, \mathrm{TaC}$, and $\mathrm{Cr}_{3} \mathrm{C}_{2}$, are always used $[12,13,17-20]$. Rong 
TABLE 1: Specifications of the raw materials applied in this work.

\begin{tabular}{lccccc}
\hline & WC & Ni & VC & TaC & SiC nanowhisker \\
\hline Purity (wt.\%) & $>99.5 \%$ & $>99.9 \%$ & $>99.0 \%$ & $>99.0 \%$ & $>99.0 \%$ \\
Oxygen content (wt.\%) & $<0.31 \%$ & - & - & - & $<0.5 \%$ \\
Size & $\begin{array}{l}0 \sim 1 \mu \mathrm{m}(97.5 \%) \\
1 \sim 2 \mu \mathrm{m}(2.5 \%)\end{array}$ & $0.7 \mu \mathrm{m}$ & $2-4 \mu \mathrm{m}$ & $1-1.5 \mu \mathrm{m}$ & Diameter $\leq 250 \mathrm{~nm}$; aspect ratio $\geq 20$ \\
\hline
\end{tabular}

et al. [12] reported that ultrafine WC-Ni cemented carbides with average WC grain size of about $330 \mathrm{~nm}$ could be fabricated by SPS with $\mathrm{VC}$ and $\mathrm{TaC}$ as grain growth inhibitors at $1350^{\circ} \mathrm{C}$. The hardness of WC- 6 wt. $\%$ Ni was about $24 \mathrm{GPa}$, which was even higher than that of the WC6 wt.\% Co cemented carbides reported in [14]. In [15], the WC-10Ni cemented carbides with grain size of about $490 \mathrm{~nm}$ have been fabricated using HFIHS at about $1250^{\circ} \mathrm{C}$ under $60 \mathrm{MPa}$ pressure. The hardness of the prepared $\mathrm{WC}-10 \mathrm{Ni}$ (about $1750 \mathrm{HV}$ ) was similar to that of the WC-10Co (about $1775 \mathrm{HV}$ ) prepared under the same condition in that work.

The hardness and flexural strength of cemented carbides can also be improved by adding some materials with higher hardness or toughness into them [11, 21, 22]. Correa et al. reported that the hardness and strength of WC-Ni cemented carbides could be improved by adding $\mathrm{SiC}$ powder into the composite system [11]. The Vickers hardness of WC-10Ni-Si was similar to that of the conventional WC-10Co. Ultra-hard material $\mathrm{cBN}$ was added to WC-Ni cemented carbides in [21]. The results indicated that the Vickers hardness of WC-NicBN cemented carbides increased from 2100 to $3200 \mathrm{HV}$ with the added fraction of $\mathrm{cBN}$ increasing from 0 up to $50 \mathrm{vol} . \%$, but the flexural strength decreased from 1950 to $1250 \mathrm{MPa}$ [21].

Because $\mathrm{SiC}$ whiskers have high strength, high elastic modulus, and good thermal stability, many studies have focused on the composites reinforced by them [22-25]. In [22], WC-Ni cemented carbides with small amount of $\mathrm{SiC}$ whisker (no more than 0.87 wt.\%) were fabricated by hotpress sintering (HPS) at $1400^{\circ} \mathrm{C}$. The flexural strength of WC$10 \mathrm{Ni}$ cemented carbides increased from about 1300 to $1700 \mathrm{MPa}$ with 0.53 wt.\% SiC whisker. Wu et al. [23] have studied the effect of $\mathrm{SiC}$ whisker addition on the mechanical properties of $\mathrm{Ti}(\mathrm{C}, \mathrm{N})$-based cermets prepared by vacuum sintering [23]. The results indicated that the fracture toughness could be improved about $29 \%$ after 1.0 wt. $\%$ SiC whisker was added compared with the cermets without whisker. The toughening mechanisms of the $\mathrm{SiC}$ whisker were characterized as crack deflection, whisker bridging, and whisker pulling out. However, Peng et al. [25] reported that due to the smaller scale and higher specific surface area of SiC nanowhisker, the $\mathrm{SiC}$ nanowhiskers were hard to uniformly dispersed when the content was higher than $2.5 \mathrm{wt} . \%$ and the $\mathrm{SiC}$ nanowhiskers would react with $\mathrm{Ni}$ to form $\mathrm{Ni}_{2} \mathrm{Si}$ phase during SPSed TiCN-based cermets.

Because of the rapid heating rate and unique joule heating principle of SPS, it was expected that the added $\mathrm{SiC}$ nanowhisker might be kept in its original state in the SPSed WC-Ni cemented carbides while the growth of WC grains was inhibited, hopefully improving the mechanical
TABLE 2: Nominal compositions of the designed samples in this work.

\begin{tabular}{lcccccc}
\hline Sample no. & Sp-0 & Sp-1 & Sp-2 & Sp-3 & Sp-4 & Sp-5 \\
\hline WC (wt.\%) & 91.00 & 90.25 & 89.50 & 88.75 & 88.00 & 87.25 \\
Ni (wt.\%) & 8.0 & 8.0 & 8.0 & 8.0 & 8.0 & 8.0 \\
VC (wt.\%) & 0.7 & 0.7 & 0.7 & 0.7 & 0.7 & 0.7 \\
TaC (wt.\%) & 0.3 & 0.3 & 0.3 & 0.3 & 0.3 & 0.3 \\
SiC nanowhisker (wt.\%) & 0 & 0.75 & 1.50 & 2.25 & 3.00 & 3.75 \\
\hline
\end{tabular}

properties of the materials, especially the mechanical strength due to the toughening effect of the added high strength whisker, which was difficult for the HPSed WC-Ni with $\mathrm{SiC}$ whisker [22]. Therefore, in this paper, WC-8 wt.\% Ni cemented carbides with varied fractions (0-3.75 wt.\%) of $\mathrm{SiC}$ nanowhisker were fabricated at $1350^{\circ} \mathrm{C}$ by SPS with the assistance of $\mathrm{VC}$ and $\mathrm{TaC}$ as $\mathrm{WC}$ grain growth inhibitors on the basis of our previous work on WC cemented carbides with different amounts of $\mathrm{Ni}(6-10 \mathrm{wt} . \%)$ as presented in [12]. The effects of $\mathrm{SiC}$ nanowhisker addition on the phase composition, microstructure, and mechanical properties of the prepared WC-Ni cemented carbides were investigated.

\section{Experimental Procedure}

2.1. Sample Preparation. The applied tungsten carbide (WC), hydroxyl-nickel (Ni), vanadium carbide (VC) and tantalum carbide $(\mathrm{TaC})$ powders, and silicon carbide nanowhisker in this work were all commercially available. Their purity, oxygen content, and size are listed in Table 1. The nominal compositions of the designed samples are presented in Table 2. During processing, the raw powders were deliberately mixed together at different milling stages and milled for disparate times in a high energy attrition mill (model: SY-1, China) with YG-6 cemented carbide balls (ISO: K20) as grinding ball and absolute alcohol as milling medium. In the first stage, the mixture of $\mathrm{WC}, \mathrm{VC}$, and $\mathrm{TaC}$ powders was milled for $44 \mathrm{~h}$ at a speed of $300 \mathrm{rpm}$, and in the second stage, $\mathrm{Ni}$ powder and $\mathrm{SiC}$ nanowhisker were added into the mixture and milled for further $4 \mathrm{~h}$ at a relatively low speed of $80 \mathrm{rpm}$, to avoid the deformation and agglomeration of $\mathrm{Ni}$ particles and the breakage of $\mathrm{SiC}$ whiskers during attritional milling. For milling, the mass ratio of ball to powder was $10: 1$ and that of powder to absolute alcohol was $3: 1$. After milling, the powder slurries were dried in a vacuum oven at $35^{\circ} \mathrm{C}$ under a pressure of $0.01 \mathrm{MPa}$. Then, the dried powders were crashed and sieved into fine powders. After that, the prepared composite powder was loaded in a cylindrical graphite die with an inner diameter of $20 \mathrm{~mm}$ and an outer diameter of 


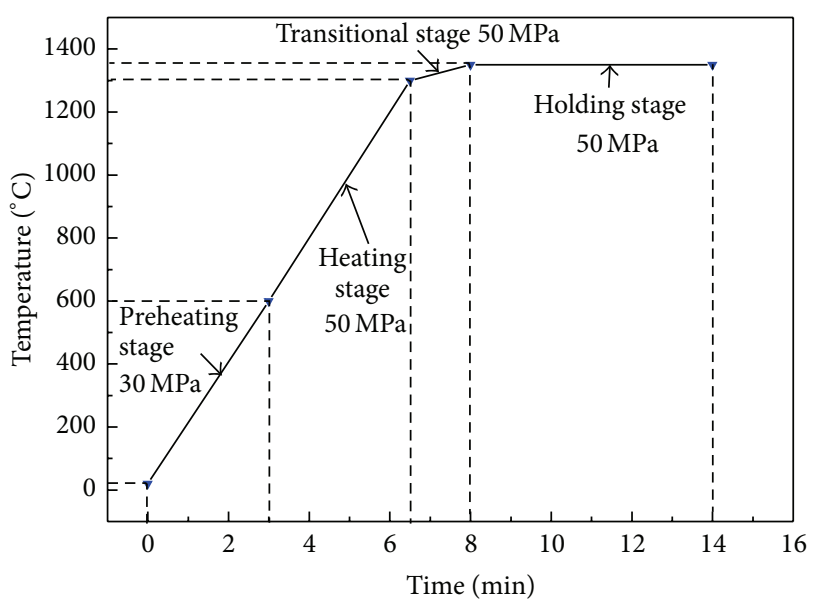

FIGURE 1: Schematic representation of the temperature and pressure varied with the heating time during SPS.

$50 \mathrm{~mm}$ and sintered by SPS (Model: SPS-1050T, Japan) in vacuum $(\leq 6 \mathrm{~Pa})$. The sintering process was divided into four stages: preheating, heating, transitional, and holding stages, as shown in Figure 1. In the preheating stage, the temperature was increased from room temperature to $600^{\circ} \mathrm{C}$ in $3 \mathrm{~min}$ with an axial pressure of $30 \mathrm{MPa}$. After this stage, the axial pressure was increased to $50 \mathrm{MPa}$ and the temperature increased from 600 to $1300^{\circ} \mathrm{C}$ in $3.5 \mathrm{~min}$. There was a transitional stage of $1.5 \mathrm{~min}$ between the heating and holding stage at the temperatures from 1300 to $1350^{\circ} \mathrm{C}$ to ensure the temperature smoothly into the holding stage. In the holding stage, the temperature and axial pressure were kept $1350^{\circ} \mathrm{C}$ and $50 \mathrm{MPa}$ for $6 \mathrm{~min}$. After sintering, the finally obtained specimens were disks of approximately $20 \mathrm{~mm}$ in diameter and $5 \mathrm{~mm}$ in height.

2.2. Materials Characterization. Before characterization, all the samples were firstly ground, machined, and mirrorpolished into rectangular bars with a dimension of about $2 \mathrm{~mm} \times 3 \mathrm{~mm} \times 15 \mathrm{~mm}$. The flexural strength was measured at room temperature by three-point bending method with an AG-IC $20 \mathrm{kN}$ Shimazu tester. During the testing, the loading rate was $0.5 \mathrm{~mm} / \mathrm{min}$ and the span length was $10 \mathrm{~mm}$. The bulk Vickers hardness (GPa) was evaluated by a LECO DM400 hardness tester with an indenting load of $1 \mathrm{kgf}$ and a dwell time of $20 \mathrm{~s}$. For each sample, the values of flexural strength and Vickers hardness are the average of five independent measurements.

In addition, the phase compositions of the as-prepared samples were identified by X-ray diffraction (XRD, $\mathrm{D} / \mathrm{max} 2550 \mathrm{HB}+/ \mathrm{PC}, \mathrm{Cu} \mathrm{K} \alpha$ and $\lambda=1.5418 \AA$ ) through continuous scanning mode with a speed of $5 \% \mathrm{~min}$. The microstructure of the specimens was examined by scanning electron microscope (SEM, LEO 1530) on the fractured and etched surfaces. Elemental analysis of the compositional phases was performed by an energy dispersive X-ray (EDX) spectroscope attached to the SEM. In addition, the etching was carried out on polished samples in a Murakami's reagent (1 $\mathrm{g}$ potassium ferricyanide, $2 \mathrm{~g}$ potassium hydroxide, and

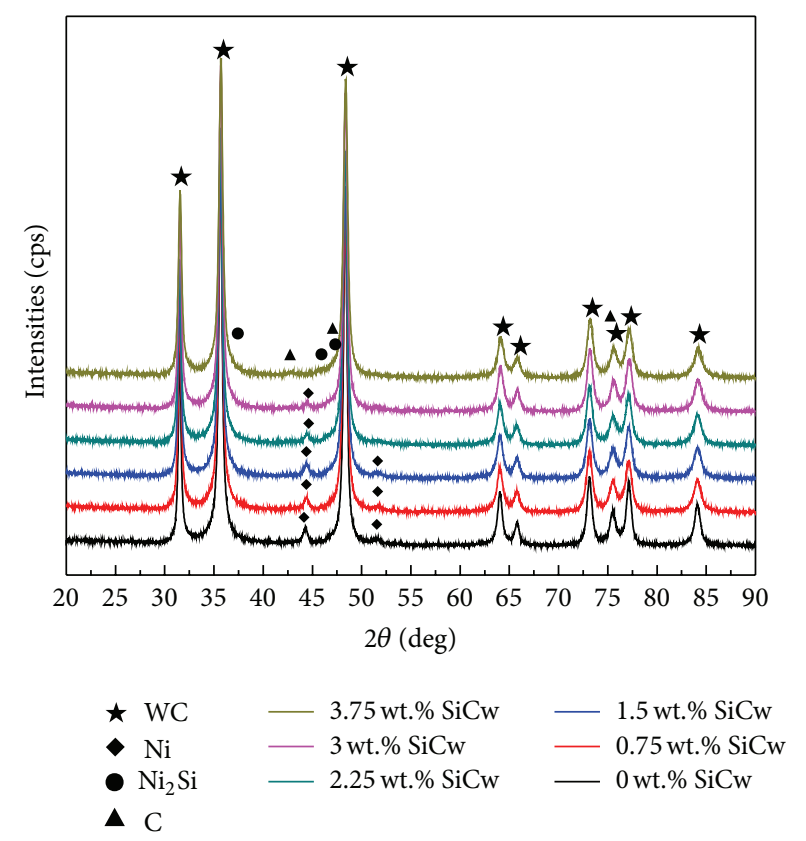

FIGURE 2: XRD patterns of the as-prepared WC-Ni cemented carbides with varied fractions of $\mathrm{SiC}$ nanowhisker.

$30 \mathrm{~g}$ water) for about $2 \mathrm{~min}$ at room temperature. The binder mean free path $(\lambda)$ and carbide grain size $\left(d_{\mathrm{WC}}\right)$ of the sample were calculated by the linear intercept method from the etched surface SEM images [26].

\section{Results and Discussion}

3.1. Phase Compositional Analysis. Figure 2 shows the XRD patterns of the as-prepared WC-Ni cemented carbides with various fractions of $\mathrm{SiC}$ nanowhisker. It can be seen that when the added fraction of SiC nanowhisker was lower than 3 wt.\%, only WC hard phase (JCPDS card: 51-0939) and Ni binder metal phase (JCPDS card: 65-0380) were identified. However, in the sample with $3.75 \mathrm{wt} . \% \mathrm{SiC}$ nanowhisker, two series of new phases, $\mathrm{Ni}_{2} \mathrm{Si}$ (JCPDS card: 03-1069) and graphite (JCPDS card: 50-1082), were detected. Moreover, with increasing fraction of $\mathrm{SiC}$ nanowhisker, the peak intensity of the Ni phase gradually faded out and even was hard to be detected in the sample with $3.75 \mathrm{wt} . \% \mathrm{SiC}$ nanowhisker. $\mathrm{Ni}_{2} \mathrm{Si}$ phase was also detected during SPSed TiCN-based cermets in [25]. Jackson et al. [27] and Schiepers et al. [28] all reported that $\mathrm{SiC}$ ceramics would react with $\mathrm{Ni}$ in vacuum when the temperature was in the range of 700 to $1150^{\circ} \mathrm{C}$ to form $\mathrm{Ni}_{2} \mathrm{Si}$ and graphite. But the reaction process was diffusion controlled and the reaction rate was very slow. The expedite reaction between the $\mathrm{Ni}$ and $\mathrm{SiC}$ nanowhisker in this work and [25] may be attributed to the unique plasma sintering model of SPS and the high special surface energy of $\mathrm{SiC}$ nanowhisker. The reaction also caused the reduction of the amount of $\mathrm{Ni}$ in the sample, resulting in weakening intensity of the Ni phase. In addition, due to the limit of XRD detection, the peak of $\mathrm{SiC}$ nanowhisker was not found in the XRD patterns. 


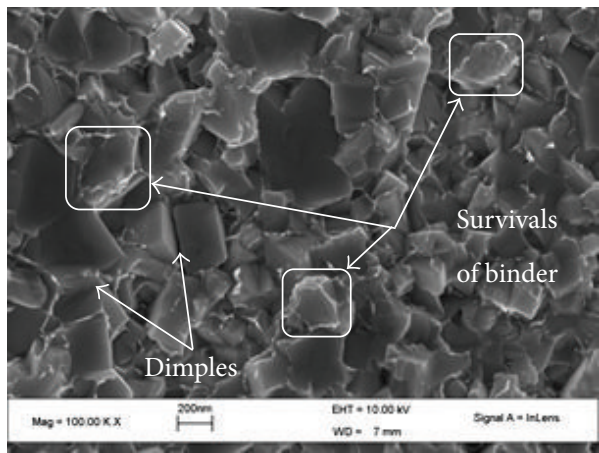

(a)

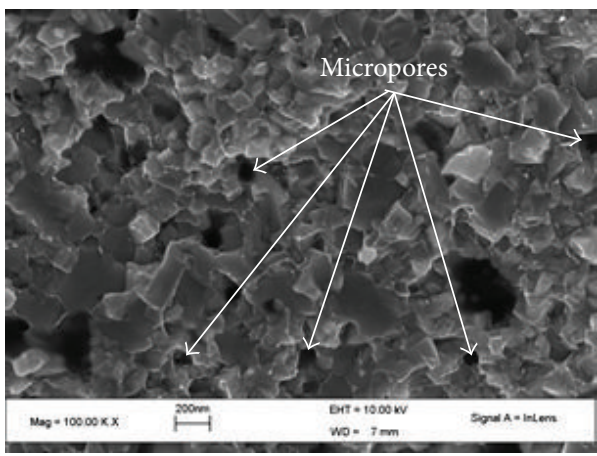

(c)

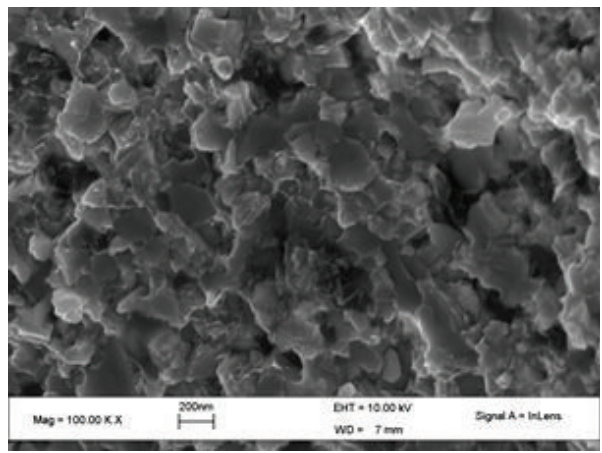

(e)

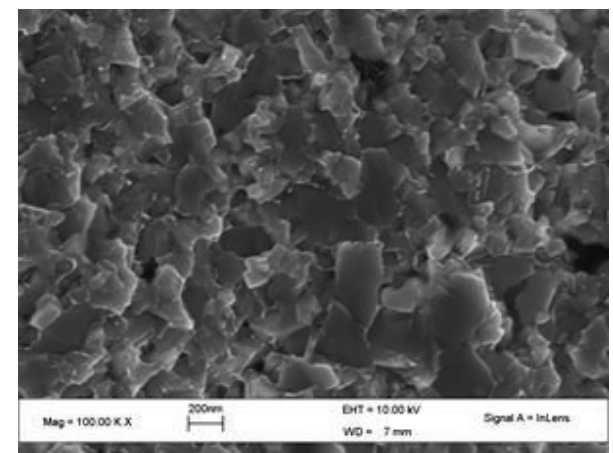

(b)

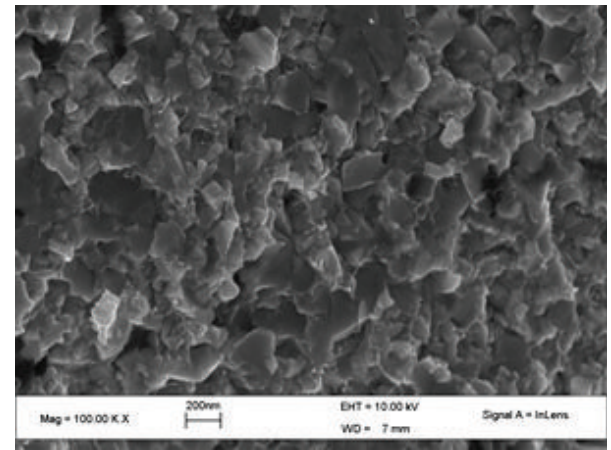

(d)

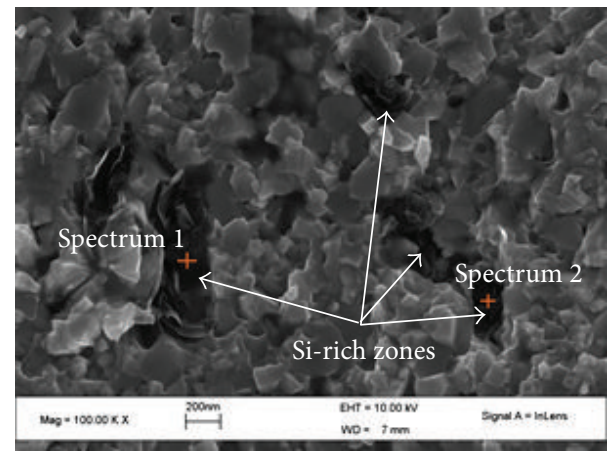

(f)

FIGURE 3: Typical SEM micrographs on the fractured surfaces of the prepared WC-Ni cemented carbides with varied fractions of SiC nanowhisker: (a) 0 wt.\%, (b) 0.75 wt.\%, (c) 1.5 wt.\%, (d) 2.25 wt.\%, (e) 3.0 wt.\%, and (f) 3.75 wt.\%.

3.2. Microstructural Characterization. Figure 3 displays typical SEM micrographs on the fractured surfaces of the prepared WC-Ni cemented carbides with various fractions of $\mathrm{SiC}$ nanowhisker. It can be seen that in the sample without $\mathrm{SiC}$ nanowhisker (as shown in Figure 3(a)), most of the fracture was through the Ni binder phase, characterized by the deep dimples and survival of binder phase, demonstrating that there was a relatively strong combination between WC and Ni binder.

However, with increasing fraction of $\mathrm{SiC}$ nanowhisker in the samples, the survival of Ni binder on the WC grains was reduced and many faceted planes appeared on the fractured surface. Compared with the sample without $\mathrm{SiC}$ nanowhisker, the samples added with $\mathrm{SiC}$ nanowhisker possess more micropores as observed on their fractured surface (as shown in Figure 3(c)), which was consistent with the result of their relative density. The reduction of the binder survival and the increased amount of micropores could be all caused by the reaction between $\mathrm{Ni}$ and $\mathrm{SiC}$ nanowhisker, suppressing the migration of binder phase during liquid sintering. Moreover, with increasing fraction of $\mathrm{SiC}$ nanowhisker, more and more aggregates (black in the micrographs as shown in Figure 3(f)) can be observed on the fractured surface. In order to figure out the composition of the black aggregates, EDX spectra were recorded on the aggregates as marked on the micrograph in Figure 3(f). The calculated results from EDX spectra are listed in Table 3. The results revealed that the black aggregates were Si-rich zones. Considering 


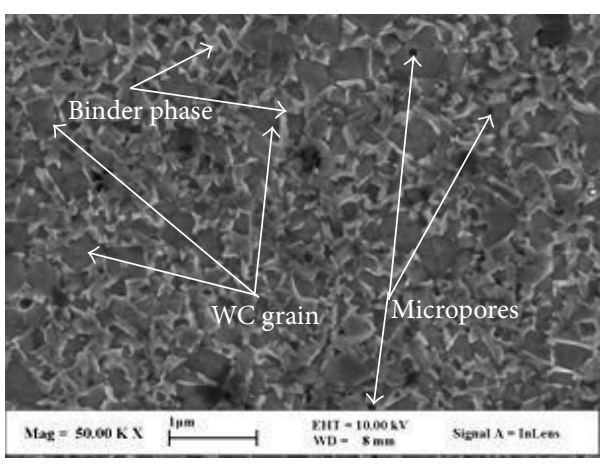

(a)

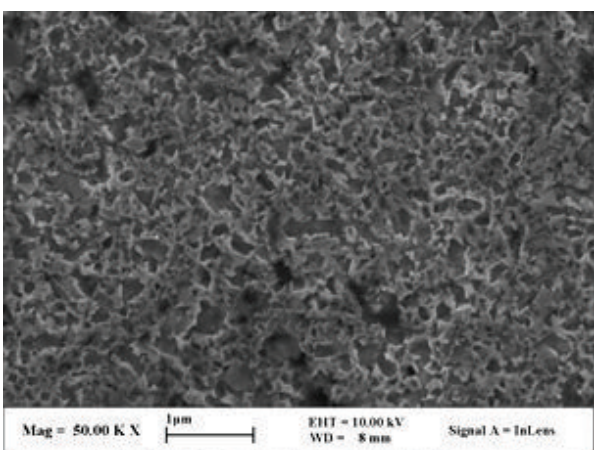

(c)

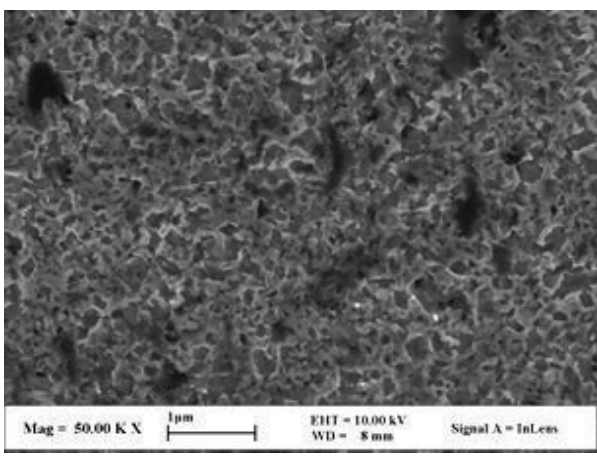

(e)

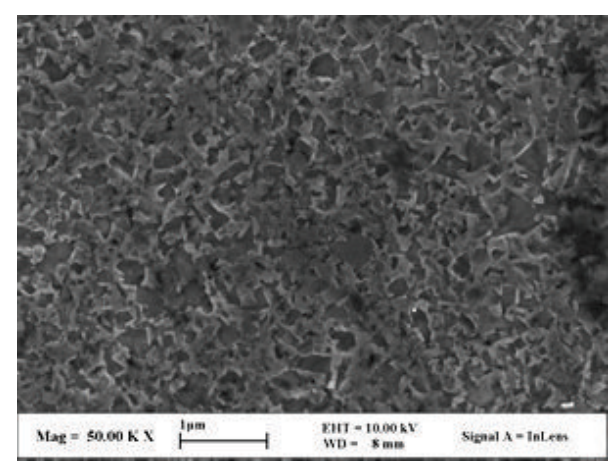

(b)

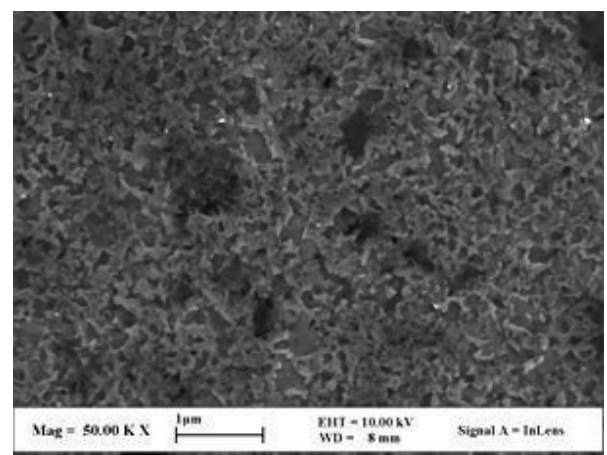

(d)

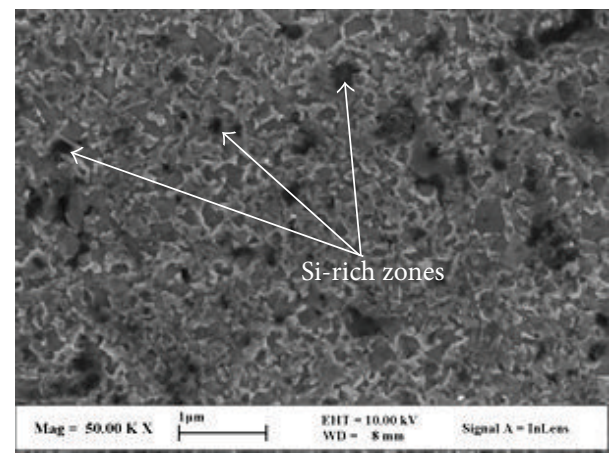

(f)

FIGURE 4: Typical SEM micrographs on the etched surfaces of the prepared WC-Ni cemented carbides with varied fractions of SiC nanowhisker: (a) 0 wt.\%, (b) 0.75 wt.\%, (c) 1.5 wt.\%, (d) 2.25 wt.\%, (e) $3.0 \mathrm{wt} . \%$, and (f) $3.75 \mathrm{wt} . \%$ (etched by Murakami’s reagent for 2 min).

TABLE 3: The constituents of the black aggregates in the prepared WC-Ni cemented carbide with $3.75 \mathrm{wt}$ \% $\mathrm{SiC}$ nanowhisker as shown in Figure 3(f).

\begin{tabular}{lcc}
\hline Elements & Spectrum 1 & Spectrum 2 \\
\hline C (at.\%) & 10.3 & 8.6 \\
O (at.\%) & 68.6 & 70.1 \\
Si (at.\%) & 21.1 & 21.3 \\
\hline
\end{tabular}

the compositions of the prepared initial composite powders, it could be suggested that the black aggregates may be formed by the agglomeration of the $\mathrm{SiC}$ nanowhisker. It should be explained that the high content of oxygen atoms on the two recorded places may be resulted from the oxidation or contamination of the sample surface.
Figure 4 presents typical SEM micrographs on the etched surfaces of the prepared WC-Ni cemented carbide with varied fractions of $\mathrm{SiC}$ nanowhisker. It can be calculated by the linear intercept method that the average WC grain size $d_{\mathrm{WC}}$ was about $400 \mathrm{~nm}$ and the average mean free path of binder $\lambda$ was about $20 \mathrm{~nm}$ for the sample without $\mathrm{SiC}$ nanowhisker, demonstrating that ultrafine WC-Ni cemented carbide was fabricated at $1350^{\circ} \mathrm{C}$ by SPS with the assistance of $\mathrm{VC}$ and $\mathrm{TaC}$ as grain growth inhibitors. After the addition of $\mathrm{SiC}$ nanowhisker into the samples, the average WC grain size decreased to about $350 \mathrm{~nm}$ as shown in Figures 4(b)-4(f). As mentioned in Section 3.1, the reaction between $\mathrm{Ni}$ and $\mathrm{SiC}$ nanowhisker would reduce the active sites of $\mathrm{Ni}$ during the SPS. And the formation of $\mathrm{Ni}_{2} \mathrm{Si}$ and graphite would decrease the wetting ability of the binder phase and suppress the solution of WC in the binder phase. Therefore, the WC grain 


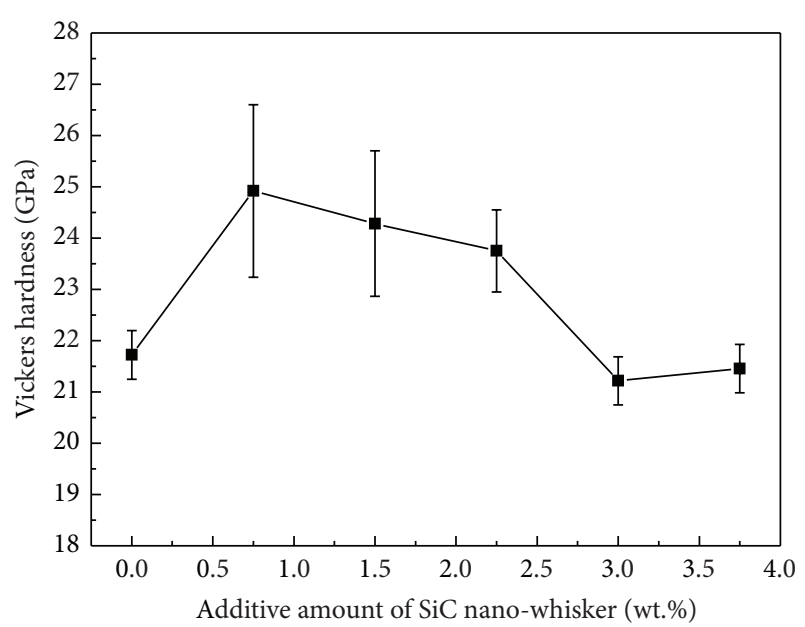

FIGURE 5: The Vickers hardness of the as-prepared WC-Ni cemented carbides with varied fractions of $\mathrm{SiC}$ nanowhisker.

growth caused by the solution/reprecipitation of WC would be suppressed. On the other hand, the $\mathrm{SiC}$ nanowhisker may also suppress the migration of WC before the formation of liquid phase. Moreover, the decrease in the wetting ability of the binder phase also caused the uneven distribution of the binder phase and more micropores as shown in Figures $3(\mathrm{c})$ and $4(\mathrm{c})$. With increasing fraction of $\mathrm{SiC}$ nanowhisker, more and more Si rich black aggregates were observed on the surface of the samples, resulting in the increase in defects in the sample, which would decrease the hardness and flexural strength of the sample.

3.3. Mechanical Properties. In order to understand the addition effect of $\mathrm{SiC}$ nanowhisker on the Vickers hardness of WC-Ni cemented carbides, the Vickers hardness is drawn as a function of the added fraction of $\mathrm{SiC}$ nano-whisker in Figure 5. From this figure, it can be seen that with increasing fraction of SiC nanowhisker, the Vickers hardness of the samples initially increased and then decreased. When the added fraction of $\mathrm{SiC}$ nanowhisker was $0.75 \mathrm{wt} . \%$, the hardness of the samples reached its maximum of about $24.9 \mathrm{GPa}$, which was even higher than the hardness of ultrafine WC$6 \mathrm{Ni}$ cemented carbides (about $24 \mathrm{GPa}$ ) obtained in [12]. The increase in Vickers hardness could be attributed to the reduced average size of WC grains when appropriate amount of $\mathrm{SiC}$ nanowhisker was added. However, with increasing fraction of $\mathrm{SiC}$ nanowhisker, the micropores and defects increased in the sample due to the existence of $\mathrm{Ni}_{2} \mathrm{Si}$ and graphite produced by the reaction between the $\mathrm{Ni}$ and $\mathrm{SiC}$ nanowhisker, which was harmful to the sample hardness. Therefore, when the added fraction of $\mathrm{SiC}$ nanowhisker was higher than $0.75 \mathrm{wt} . \%$, the hardness of the sample gradually decreased. What is more, when the added fraction of SiC nanowhisker was higher than $2.25 \mathrm{wt} . \%$, the Si-rich aggregates became more and more serious as observed in Figures $3(f)$ and $4(f)$, which would also decrease the hardness of the cemented carbides.

Figure 6 illustrates the variation of the flexural strength of the obtained WC-Ni cemented carbides with the added

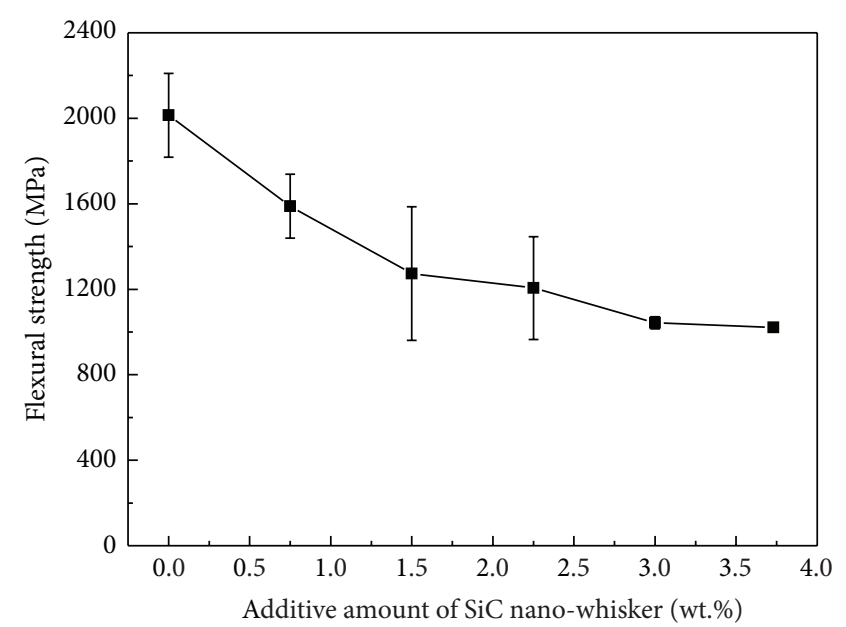

FIGURE 6: The flexural strength of the as-prepared WC-Ni cemented carbides with varied fractions of $\mathrm{SiC}$ nanowhisker.

fraction of $\mathrm{SiC}$ nanowhisker. The result indicated that with increasing fraction of $\mathrm{SiC}$ nanowhisker into the samples, the flexural strength gradually decreased. When the added fraction of $\mathrm{SiC}$ nanowhisker was $3.75 \mathrm{wt} . \%$, the flexural strength of the obtained cemented carbides was only about $1000 \mathrm{MPa}$, which was approximately $1000 \mathrm{MPa}$ lower than that of the sample without $\mathrm{SiC}$ nanowhisker. The reason for such phenomenon can be explained as follows. First, the bending test was sensitive to defects, such as micropores and agglomeration in the samples. As mentioned in Section 3.2, the addition of $\mathrm{SiC}$ nanowhisker would decrease the wetting ability of binder phase and suppress the migration of liquid binder phase, which was harmful to the densification of the samples and caused more defects in them. These defects may initiate the crack during the bending test. With more $\mathrm{SiC}$ nanowhisker, its agglomeration became more serious as shown in Figures 3 and 4, which would be also harmful to the flexural strength. Moreover, the flexural strengths of the produced $\mathrm{Ni}_{2} \mathrm{Si}$ and graphite by the reaction between $\mathrm{Ni}$ and $\mathrm{SiC}$ nanowhisker were relatively lower than those of $\mathrm{Ni}$ and $\mathrm{SiC}$ whisker, which would also reduce the flexural strength of the obtained samples. In addition, the reaction consumes the Ni binder, which was confirmed by the decreased amount of survival Ni binder and deep dimples as seen in Figure 3 with increasing fraction of $\mathrm{SiC}$ nanowhisker into the sample and would weaken the combination between WC grains. Consequently, the flexural strength of the samples decreased with increasing fraction of $\mathrm{SiC}$ nanowhisker. Such results suggested that, because of the reaction between $\mathrm{Ni}$ and $\mathrm{SiC}$ nanowhisker during SPS, the addition of $\mathrm{SiC}$ nanowhisker was of no much help to improve the flexural strength of WC$\mathrm{Ni}$ cemented carbides during SPS.

\section{Conclusions}

Ultrafine WC-Ni cemented carbides with varied fractions of $\mathrm{SiC}$ nanowhisker were fabricated by SPS at $1350^{\circ} \mathrm{C}$ with the assistance of $\mathrm{VC}$ and $\mathrm{TaC}$ as WC grain growth inhibitors. The reaction between $\mathrm{Ni}$ and $\mathrm{SiC}$ nanowhisker happened 
during SPS, forming $\mathrm{Ni}_{2} \mathrm{Si}$ and graphite, which was different from the results of WC-Ni cemented carbides fabricated by hot-press sintering. With the addition of $\mathrm{SiC}$ nanowhisker, the average WC grain size decreased from 400 to $350 \mathrm{~nm}$. However, with increasing fraction of $\mathrm{SiC}$ nanowhisker, more and more Si-rich aggregates appeared. The Vickers hardness initially increased and then decreased with increasing $\mathrm{SiC}$ nanowhisker fraction, reaching its maximum value at about 24.9 GPa when 0.75 wt.\% SiC nanowhisker was added. With increasing fraction of $\mathrm{SiC}$ nanowhisker, the flexural strength gradually decreased.

\section{Conflict of Interests}

The authors declare that they have no conflict of interests regarding the publication of this paper.

\section{Acknowledgments}

This work was supported by Grand Survey on Land and Nature Sources of China sponsored by China Geological Survey (Grant no. 1212010916026), the Excellent Adviser Foundation in China University of Geosciences from the Fundamental Research Funds for the Central Universities, and National Key Technology R \& D Program of China (Grant no. 2011BAB03B08).

\section{References}

[1] L. J. Prakash, "Application of fine grained tungsten carbide based cemented carbides," International Journal of Refractory Metals and Hard Materials, vol. 13, no. 5, p. 257, 1995.

[2] X. Ren, H. Miao, and Z. Peng, "A review of cemented carbides for rock drilling: an old but still tough challenge in geoengineering," International Journal of Refractory Metals and Hard Materials, vol. 39, pp. 61-77, 2013.

[3] G. Gille, B. Szesny, K. Dreyer et al., "Submicron and ultrafine grained hardmetals for microdrills and metal cutting inserts," International Journal of Refractory Metals and Hard Materials, vol. 20, no. 1, pp. 3-22, 2002.

[4] H. Engqvist, G. A. Botton, S. Ederyd, M. Phaneuf, J. Fondelius, and N. Axén, "Wear phenomena on WC-based face seal rings," International Journal of Refractory Metals and Hard Materials, vol. 18, no. 1, pp. 39-46, 2000.

[5] A. M. Human and H. E. Exner, "Electrochemical behaviour of tungsten-carbide hardmetals," Materials Science and Engineering A, vol. 209, no. 1-2, pp. 180-191, 1996.

[6] G. S. Upadhyaya, "Materials science of cemented carbides-an overview," Materials and Design, vol. 22, no. 6, pp. 483-489, 2001.

[7] A. M. Human and H. E. Exner, "The relationship between electrochemical behaviour and in-service corrosion of WC based cemented carbides," International Journal of Refractory Metals and Hard Materials, vol. 15, no. 1-3, pp. 65-71, 1997.

[8] H.-C. Kim, I.-J. Shon, J.-K. Yoon, and J.-M. Doh, "Comparison of sintering behavior and mechanical properties between WC8Co and WC-8Ni hard materials produced by high-frequency induction heating sintering," Metals and Materials International, vol. 12, no. 2, pp. 141-146, 2006.
[9] K. Bonny, P. De Baets, J. Van Wittenberghe et al., "Influence of electrical discharge machining on sliding friction and wear of WCNi cemented carbide," Tribology International, vol. 43, no. 12, pp. 2333-2344, 2010.

[10] K. Bonny, P. De Baets, J. Vleugels, S. Huang, and B. Lauwers, "Dry reciprocating sliding friction and wear response of WC-Ni cemented carbides," Tribology Letters, vol. 31, no. 3, pp. 199-209, 2008.

[11] E. O. Correa, J. N. Santos, and A. N. Klein, "Microstructure and mechanical properties of WC Ni-Si based cemented carbides developed by powder metallurgy," International Journal of Refractory Metals and Hard Materials, vol. 28, no. 5, pp. 572$575,2010$.

[12] H. Rong, Z. Peng, X. Ren et al., "Ultrafine WC-Ni cemented carbides fabricated by spark plasma sintering," Materials Science and Engineering A, vol. 532, pp. 543-547, 2012.

[13] H.-C. Kim, I.-J. Shon, J.-K. Yoon, J.-M. Doh, and Z. A. Munir, "Rapid sintering of ultrafine WC-Ni cermets," International Journal of Refractory Metals and Hard Materials, vol. 24, no. 6, pp. 427-431, 2006.

[14] A. Mukhopadhyay and B. Basu, "Recent developments on WCbased bulk composites," Journal of Materials Science, vol. 46, no. 3, pp. 571-589, 2011.

[15] I.-J. Shon, I.-K. Jeong, I.-Y. Ko, J.-M. Doh, and K.-D. Woo, "Sintering behavior and mechanical properties of WC-10Co, WC-10Ni and WC-10Fe hard materials produced by highfrequency induction heated sintering," Ceramics International, vol. 35, no. 1, pp. 339-344, 2009.

[16] Z. Z. Fang, X. Wang, T. Ryu, K. S. Hwang, and H. Y. Sohn, "Synthesis, sintering, and mechanical properties of nanocrystalline cemented tungsten carbide-a review," International Journal of Refractory Metals and Hard Materials, vol. 27, no. 2, pp. 288-299, 2009.

[17] V. Bonache, M. D. Salvador, V. G. Rocha, and A. Borrell, "Microstructural control of ultrafine and nanocrystalline WC$12 \mathrm{Co}-\mathrm{VC} / \mathrm{Cr}_{3} \mathrm{C}_{2}$ mixture by spark plasma sintering," Ceramics International, vol. 37, no. 3, pp. 1139-1142, 2011.

[18] L. Sun, T. Yang, C. Jia, and J. Xiong, "VC, $\mathrm{Cr}_{3} \mathrm{C}_{2}$ doped ultrafine WC-Co cemented carbides prepared by spark plasma sintering," International Journal of Refractory Metals and Hard Materials, vol. 29, no. 2, pp. 147-152, 2011.

[19] S. Lay, S. Hamar-Thibault, and A. Lackner, "Location of VC in VC, $\mathrm{Cr}_{3} \mathrm{C}_{2}$ codoped WC-Co cermets by HREM and EELS," International Journal of Refractory Metals and Hard Materials, vol. 20, no. 1, pp. 61-69, 2002.

[20] B. Wittmann, W.-D. Schubert, and B. Lux, "WC grain growth and grain growth inhibition in nickel and iron binder hardmetals," International Journal of Refractory Metals and Hard Materials, vol. 20, no. 1, pp. 51-60, 2002.

[21] H. Rong, Z. Peng, X. Ren et al., "Microstructure and mechanical properties of ultrafine WC-Ni-VC-TaC-cBN cemented carbides fabricated by spark plasma sintering," International Journal of Refractory Metals and Hard Materials, vol. 29, no. 6, pp. 733738, 2011.

[22] X. Ren, Z. Peng, Y. Peng et al., "Effect of SiC nano-whisker addition on WC-Ni based cemented carbides fabricated by hot-press sintering," International Journal of Refractory Metals and Hard Materials, vol. 36, pp. 294-299, 2013.

[23] P. Wu, Y. Zheng, Y. Zhao, and H. Yu, "Effect of SiC whisker addition on the microstructures and mechanical properties of $\mathrm{Ti}(\mathrm{C}$, N)-based cermets," Materials and Design, vol. 32, no. 2, pp. 951956, 2011. 
[24] P. F. Becher and G. C. Wei, "Toughening behavior in SicWhisker-reinforced alumina," Journal of the American Ceramic Society, vol. 67, no. 12, pp. c267-c269, 1984.

[25] Y. Peng, Z. Peng, X. Ren et al., "Effect of SiC nano-whisker addition on TiCN-based cermets prepared by spark plasma sintering," International Journal of Refractory Metals and Hard Materials, vol. 34, pp. 36-40, 2012.

[26] J.-H. Han and D.-Y. Kim, "Determination of three-dimensional grain size distribution by linear intercept measurement," Acta Materialia, vol. 46, no. 6, pp. 2021-2028, 1998.

[27] M. R. Jackson, R. L. Mehan, A. M. Davis, and E. L. Hall, "Solid state SiC/Ni alloy reaction," Metallurgical Transactions A, vol. 14, no. 3, pp. 355-364, 1983.

[28] R. C. J. Schiepers, F. J. J. van Loo, and G. de With, "Reactions between $\alpha$-silicon carbide ceramic and nickel or iron," Journal of the American Ceramic Society, vol. 71, no. 6, pp. C-284-C-287, 1988. 

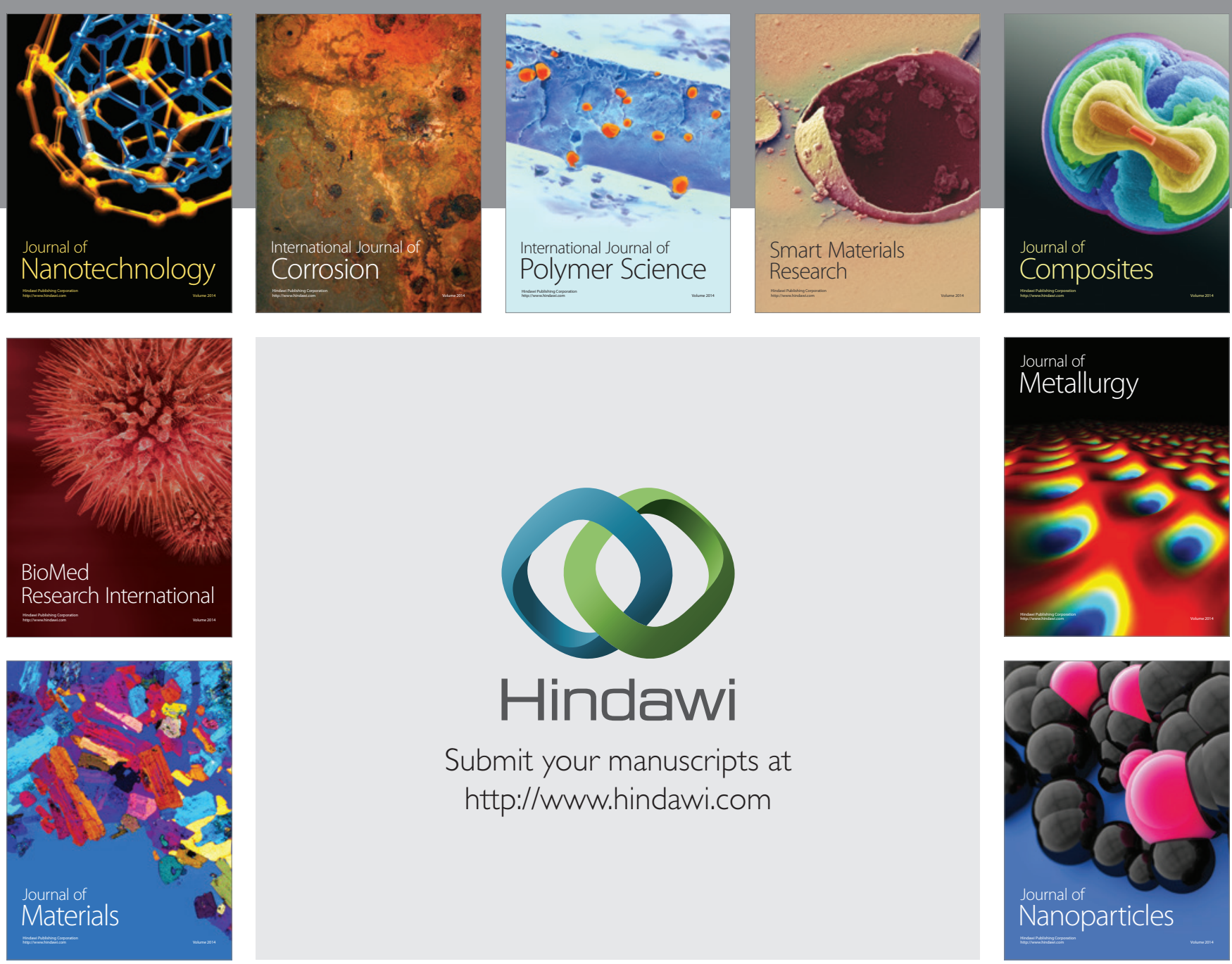

Submit your manuscripts at http://www.hindawi.com
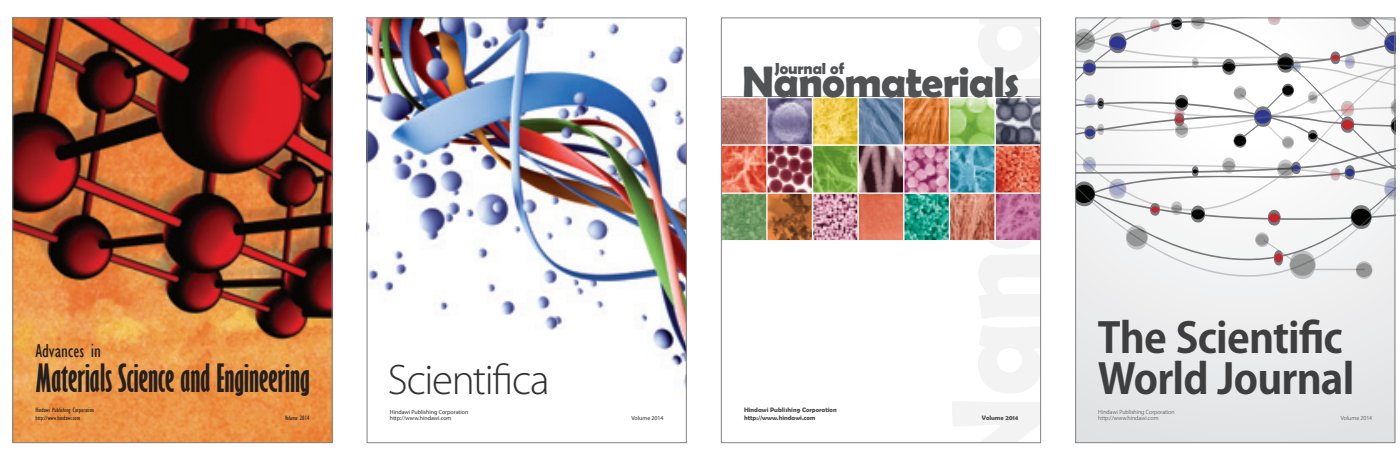

\section{The Scientific World Journal}
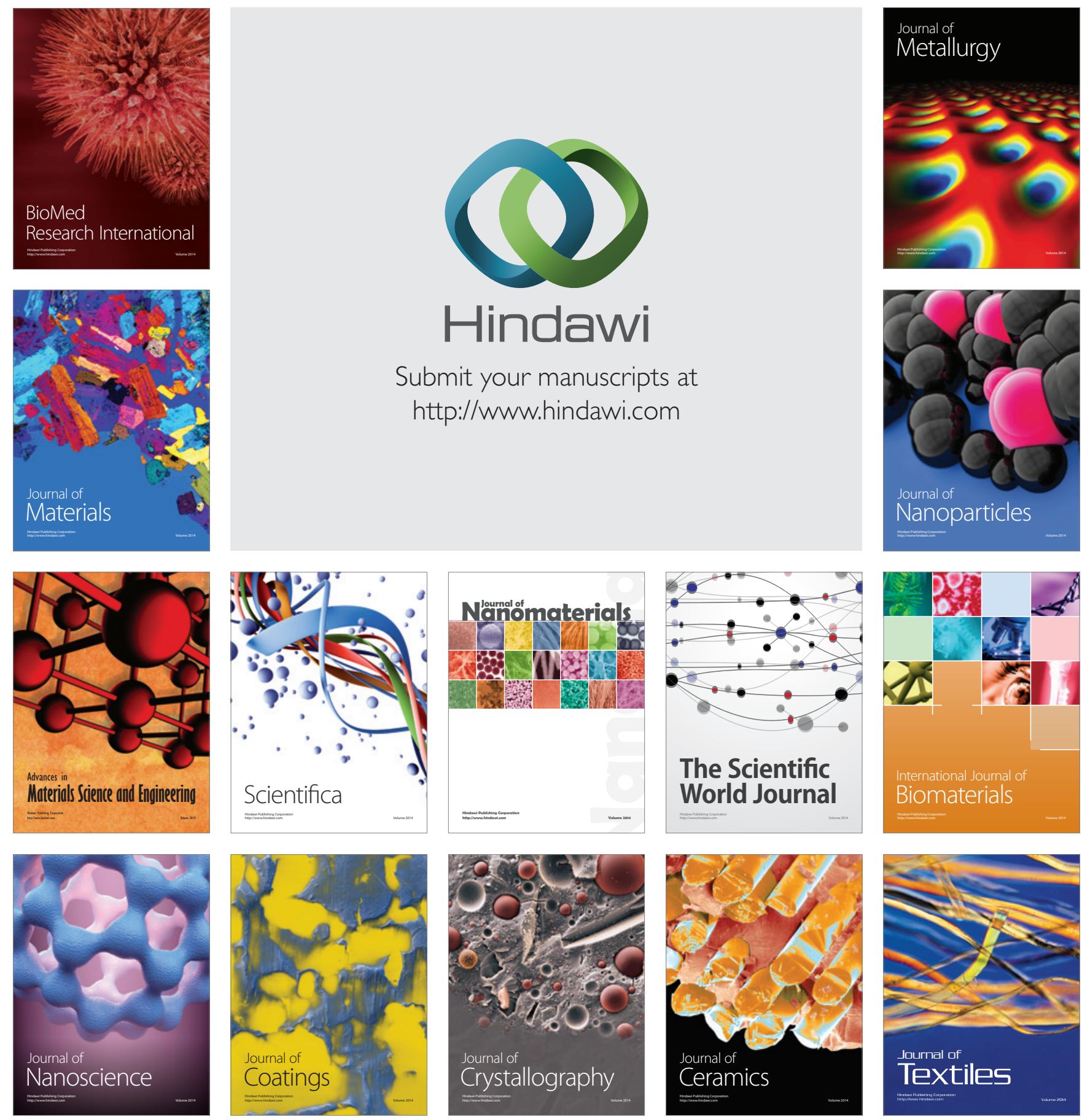